\title{
A numerical simulation of ionospheric and atmospheric variations associated with the Sumatra earthquake on December 26, 2004
}

\author{
H. Shinagawa ${ }^{1}$, T. Iyemori ${ }^{2}$, S. Saito ${ }^{1}$, and T. Maruyama ${ }^{1}$ \\ ${ }^{1}$ National Institute of Information and Communications Technology, Koganei, Tokyo 184-8795, Japan \\ ${ }^{2}$ Graduate School of Science, Kyoto University, Kyoto, Japan
}

(Received January 17, 2007; Revised July 9, 2007; Accepted July 20, 2007; Online published September 28, 2007)

\begin{abstract}
In the Sumatra earthquake that occurred on December 26, 2004, significant ionospheric variations were detected immediately after the earthquake in both the TEC (total electron content) data of GPS (Global Positioning System) and the ionosonde data. A magnetic pulsation with a period of about 4 min was also observed in Phimai, Thailand. Recent studies have suggested that these events are associated with acoustic waves excited by a sudden large-scale displacement of the sea surface around the epicenter. In order to study these phenomena quantitatively, a time-dependent two-dimensional nonhydrostatic compressible atmosphere-ionosphere model has been used and compared with relevant data. By modeling in sea surface perturbation, we were able to reproduce an atmospheric oscillation with a period of about $4 \mathrm{~min}$ in the upper atmosphere above the epicenter. The electron density variations observed by GPS/TEC and by ionosondes were also reproduced fairly well. We found that the observed TIDs (traveling ionospheric disturbances) with long periods are caused by the ducted thermospheric gravity waves produced in the thermosphere through acoustic pulse from the epicenter. The good overall agreement between the simulation results and observations indicates that numerical simulation with the nonhydrostatic compressible atmosphere-ionosphere model could be a useful tool to investigate the relationship between variations in the upper atmosphere and various sources of disturbances in the lower atmosphere.
\end{abstract}

Key words: Ionosphere, thermosphere, atmosphere, Sumatra, earthquake, acoustic wave, gravity wave, numerical simulation.

\section{Introduction}

In the lower atmosphere of the Earth, acoustic-gravity waves are generated by various kinds of natural and artificial sources, such as cumulus clouds, typhoons, earthquakes, tsunamis, volcanic eruptions, meteor impacts, nuclear explosions, rocket launches, among others. Previous theoretical and observational studies have suggested that acoustic-gravity waves are induced by such sources and that they can propagate up to the upper atmosphere, producing temporal and spatial variations in the thermosphere and in the ionosphere (e.g., Whipple, 1930; Hines, 1960; Leonard and Barnes, 1965; Davies and Baker, 1965; Row, 1967; Liu and Yeh, 1971; Georges, 1973; Francis, 1975; Ogawa et al., 1982; Roberts et al., 1982; Liu et al., 1982; Tanaka et al., 1984; Blanc, 1985; Kelly et al., 1985; Igarashi et al., 1994; Kanamori and Mori, 1992; Kanamori et al., 1994; Li et al., 1994; Pokhotelov et al., 1995; Davies and Archambeau, 1998; Hickey et al., 2001; Walterscheid et al., 2003; Heki and Ping, 2005).

Since the amplitude of atmospheric waves is approximately inversely proportional to the square root of the mass density of the atmosphere, even a small atmospheric perturbation near the surface results in a considerably larger displacement in the upper atmosphere. Therefore, distur-

Copyright (c) The Society of Geomagnetism and Earth, Planetary and Space Sciences (SGEPSS); The Seismological Society of Japan; The Volcanological Society of Japan; The Geodetic Society of Japan; The Japanese Society for Planetary Sciences; TERRAPUB bances in the lower atmosphere would have a significant influence on the dynamics and the energetics of the upper atmosphere, suggesting a possibility that surface disturbances can be monitored by observing the ionosphere in real time. However, a direct relationship between surface phenomena and upper atmospheric variations has not yet been fully understood because the upper atmosphere is easily disturbed by many other sources in both the atmosphere and in space, such as auroral activities, wind shear in the mesopause region, and the electric field generated by the ionospheric dynamo. Unambiguous variations in the ionosphere have been found only when extremely large energy is given impulsively in the lower atmosphere.

One of the best-known events is the Alaskan earthquake that occurred at 0336 UT on March 28, 1964, in which large ionospheric and thermospheric variations were observed after the earthquake. Theoretical and observational studies suggested that displacement of the surface generated acoustic-gravity waves and caused the upper atmospheric disturbances (Leonard and Barnes, 1965; Davies and Baker, 1965; Row, 1967; Liu and Yeh, 1971; Liu et al., 1982; Kelly et al., 1985). Another notable event is the eruptions of Mount St. Helens on May 18, 1980. In this event, large ionospheric variations, which appear to be associated with Lamb mode waves generated by the eruption in the atmosphere, were detected (Ogawa et al., 1982; Liu et al., 1982; Roberts et al., 1982). It is also noted that nuclear explosion in the atmosphere on October 1961 at Novaya Zemlya, 
Russia, also caused clear traveling ionospheric disturbances (Row, 1967; Francis, 1975).

Recently, even more distinct influences of the lower atmospheric phenomena on the upper atmosphere have been detected following the earthquake that occurred in West Sumatra, Indonesia, at 0058 UT on December 26, 2004. Significant ionospheric disturbances associated with the earthquake were observed (DasGupta et al., 2006; Otsuka et al., 2006; Heki et al., 2006). Otsuka et al. (2006) analyzed Global Positioning System (GPS) data, which was obtained at two sites in Sumatra and at three sites in Thailand, to investigate total electron content (TEC) variations. They reported that at 14-40 min after the earthquake, TEC enhancements of 1.6-6.9 TEC unit (TECU) were observed at the sub-ionospheric points, which are located at 360$2000 \mathrm{~km}$ north from the epicenter. From the time delays of the observed TEC enhancements, they suggested that acoustic waves generated by the earthquake propagated into the ionosphere at the sound speed to cause the TEC variations. Smaller TEC enhancement of 0.6 TECU was observed at the south of the epicenter, and there is no TEC enhancement at the east of the epicenter.

In addition to the ionospheric variations, Iyemori et al. (2005) discovered unusual magnetic pulsations at Phimai in Thailand after the earthquake. They analyzed the ground magnetic field data and found a long-period Pc5 pulsation shortly after the origin time of the Sumatra earthquake. The localized nature and the period of oscillations suggest that the long-period magnetic pulsation was generated by dynamo action in the lower ionosphere, set up by an atmospheric pressure pulse which propagated vertically as an acoustic wave when the ocean floor suddenly moved vertically.

In order to examine the physical processes of those phenomena quantitatively, we developed and used a two-dimensional nonhydrostatic compressible atmosphereionosphere model. We present here the results of numerical simulation of variations in the ionosphere and the atmosphere caused by the Sumatra earthquake. The results are compared with the observed magnetic pulsation data, GPS/TEC data, and ionosonde data obtained on the day of the Sumatra earthquake.

\section{Simulation Model}

A two-dimensional atmosphere-ionosphere model is used to study the variations in the ionosphere and thermosphere driven by the atmospheric perturbation at the sea surface. The neutral atmosphere is treated as a nonhydrostatic compressible fluid, and the ionosphere is treated as a single-fluid collisional plasma. The modeling method of the neutral atmosphere is basically the same as that of Shinagawa and Oyama (2006). The simulation domain and basic configuration of the model are illustrated schematically in Fig. 1. The altitude region in the model is from $0 \mathrm{~km}$ (the surface) to $700 \mathrm{~km}$, and the horizontal region is from the magnetic North Pole to the magnetic South Pole. The vertical grid size is $2 \mathrm{~km}$, and the horizontal grid size is $20 \mathrm{~km}$. The time step for the numerical simulation is $0.2 \mathrm{~s}$. The ion is assumed to move only along magnetic field lines, and the ion drift driven by external electric fields is not included.

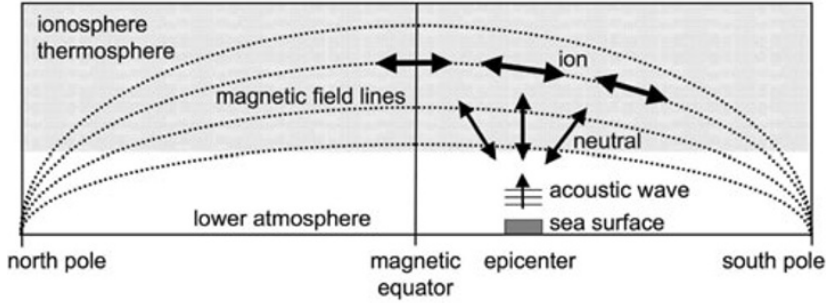

Fig. 1. Schematic figure of the simulation domain: $0-700 \mathrm{~km}$ in altitude, and the magnetic North Pole to the magnetic South Pole in latitude. The magnetic field is assumed to be dipole. Ions are assumed to move only along the magnetic field lines, and effects of the external electric field are neglected.

The magnetic field is assumed to be dipole. In the simulation, neutral motion drives ion motion along magnetic field lines through ion-neutral collision. The momentum transfer from ion motion to neutral motion is neglected because it is much smaller than other terms in the neutral momentum equation in the present simulation.

The basic state of the neutral atmosphere is taken from the empirical model (MSISE-90) (Hedin et al., 1991). The atmospheric densities and temperatures are obtained from the model by setting values for Phimai $\left(15.2^{\circ} \mathrm{N}, 102.6^{\circ} \mathrm{E}\right)$ as a typical low-latitude atmosphere. The date and time for the atmospheric model are set to be the onset date and time of the Sumatra earthquake, i.e., 0900 UT. The F10.7 cm value (the index of solar extreme ultraviolet flux) is set to be 120 for the MSIS model, which turned out to be somewhat larger than the actually measured value $(\sim 90)$ on the day of the earthquake. The index for magnetic activity, $A P$, is taken to be 4 .

The altitude profiles of the neutral mass density and temperature are shown in Fig. 2(a) and (b), respectively. The atmosphere is assumed to have no horizontal dependence, and the initial neutral velocities are taken to be zero. This means that the effects of the background wind are not included in this calculation. It is also assumed that the background atmosphere does not change throughout the simulation.

In the ionospheric model, a simplified single-fluid ionospheric model is employed, and the following continuity and momentum equations are solved for given plasma temperature profiles.

Continuity equation:

$$
\frac{\partial n_{i}}{\partial t}=-\nabla \bullet\left(n_{i} \mathbf{v}_{i \|}\right)+P_{i}-L_{i}
$$

Momentum equation (ion diffusion equation):

$$
\mathbf{v}_{i \|}=-\frac{1}{m_{i} n_{i} v_{i n}} \nabla_{\|} p+\frac{\mathbf{g}_{\|}}{v_{i n}}+\mathbf{v}_{n \|}
$$

where $n_{i}$ is the ion density, $\mathbf{v}_{i}$ is the ion velocity, $P_{i}$ is the ion production rate, $L_{i}$ is the ion loss rate, $m_{i}$ is the ion mass, $v_{i n}$ is the ion-neutral collision frequency, $p$ is the plasma pressure (sum of ion pressure and electron pressure), $\mathbf{g}$ is the gravity acceleration, and $\mathbf{v}_{n}$ is the neutral velocity. Subscripts $i$ and $n$ denote ion and neutral species, respectively. Subscript || indicates a vector component along the magnetic field line. The following simple analytical formula is used for the ion production rate $P_{i}$ (cf. Banks and 

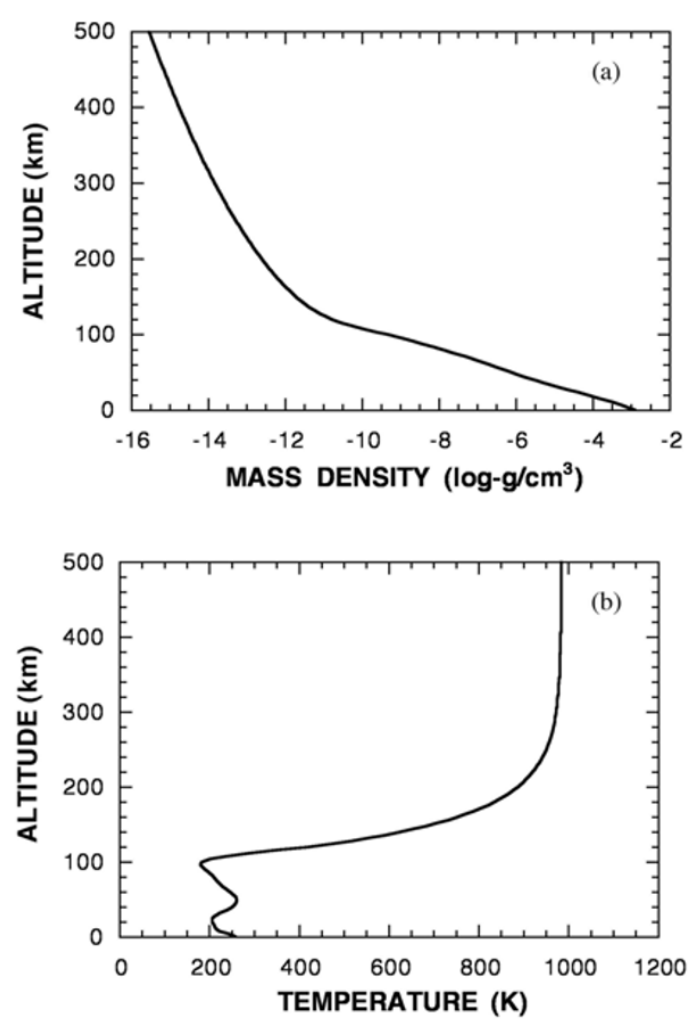

Fig. 2. Background atmospheric model used in the simulation. (a) Altitude profile of the mass density $\left(\log \mathrm{g} \mathrm{cm}^{-3}\right)$. (b) Neutral temperature profile $(\mathrm{K})$.

Kockarts, 1973).

$$
P_{i}=P_{i, \max } \exp [1-Z-\sec \chi \exp (-Z)]
$$

where $P_{i, \max }$ is the peak ionization rate and is taken to be $2 \times 10^{3} \mathrm{~cm}^{-3} \mathrm{~s}^{-1}, Z=\left(z-z_{\max }\right) / H, z$ is the altitude from the surface, $z_{\max }$ is the peak ionization altitude and is taken to be $150 \mathrm{~km}, \chi$ is the latitude from the magnetic equator, and $H$ is the neutral scale height. Values for $v_{i n}$ and $L_{i}$ are taken from Schunk and Nagy (1980).

In the simulation, only the ion density of $\mathrm{O}^{+}$, which is the major ion in the $F$ region, is included because the electron density in the $E$ region is not significantly affected by the neutral dynamics and because the electron density in the $E$ region does not make a major contribution to TEC. Ion production and ion-neutral chemistry for $\mathrm{O}^{+}$are included, but the ion production rate is fixed in time; that is, diurnal variation is not included. Seasonal effects of the ion production rate are also not considered. The plasma temperatures are taken to be twice as large as neutral temperatures at all altitudes. The ion density below $100 \mathrm{~km}$ is set to be $10^{3} \mathrm{~cm}^{-3}$, and is used as the lower boundary condition for the ionospheric model. The diffusive equilibrium condition is used for the upper boundary condition. These assumptions and simplifications are reasonable for the present calculations because our interest lies in the relative variations in the electron density in the $F$ region for only 1 or $2 \mathrm{~h}$ after the earthquake.

The initial electron density distribution is illustrated as contours in Fig. 3, in which the region within $4000 \mathrm{~km}$ from

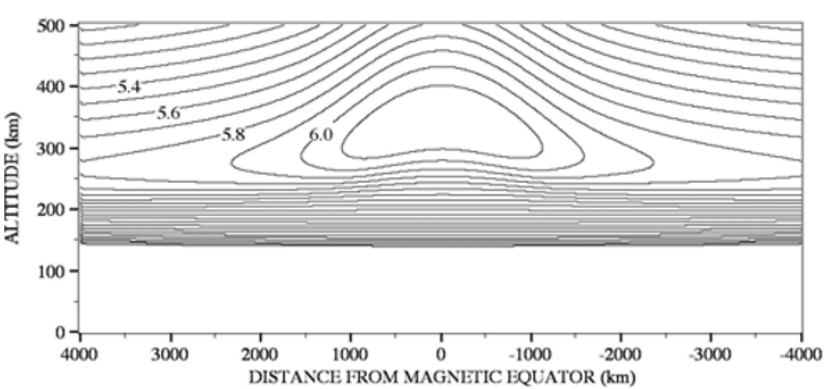

Fig. 3. Contours of the initial electron density distribution used in the simulation. Only the horizontal region between $4000 \mathrm{~km}$ north and south with respect to the magnetic equator is shown. Numbers are in the unit of $\log \mathrm{cm}^{-3}$.

the equator in latitude and $0-700 \mathrm{~km}$ in altitude is shown. The initial steady-state condition for the ionosphere is obtained by running the ionospheric model for several days in the model for the fixed neutral atmosphere and the given ionization rate profile. The peak electron density is larger at lower latitudes partly because the ionization rate is larger and partly because the vertical ion diffusion is more inhibited at lower latitudes. This initial distribution of the electron density may not be very realistic because the ionization rate reaches a maximum in the southern hemisphere in December and because the neutral wind tends to be northward on the day of the earthquake. The former effect brings the ionization peak in the southern hemisphere, and the latter effect moves the ionization peak to the northward. Since we are mainly interested in the relative variation in the ionosphere associated with the atmospheric waves, such a simple ionospheric model would be good enough for the present study.

The displacement of the sea surface is incorporated by giving a vertical velocity for the neutral atmosphere as the lower boundary condition. At the lower boundary, a sinusoidal variation with a period of $10 \mathrm{~s}$ and the vertical velocity amplitude of $1 \mathrm{~m} / \mathrm{s}$ is given for the vertical velocity for only one period, starting with an upward motion. This perturbation is rather arbitrary, but our test calculations suggest that as long as the displacement is fast enough to generate acoustic waves, the effect on the ionosphere is approximately the same.

It is noted that the epicenter is located at about $3^{\circ}$ north in the geographic coordinate, but in the geomagnetic coordinate, it is about $-6.25^{\circ}$ south of the magnetic equator. Thus, the center of the displacement region in the model is located at $-6.25^{\circ}$ south in the geomagnetic coordinate. The displacement region has a latitudinal width of $200 \mathrm{~km}$, which is taken from the observations that the initial displacement of the sea surface has a width of about $200 \mathrm{~km}$. However, various observations indicate that several more displacements also occurred successively following the initial displacement (Bilham, 2005; Tanioka et al., 2006; Hirata et al., 2006). In the model, only the initial displacement at the sea surface, which appears to be the largest, is considered. Although the input parameters have some uncertainties, our calculations imply that the basic nature of acoustic-gravity waves, such as phase velocities and their 
effects on the ionosphere, turned out to be rather insensitive to the inputs as long as the initial perturbation is rapid enough to generate acoustic waves.

\section{Results}

Starting from the steady-state ionosphere and atmosphere described in the previous section, a sudden perturbation in the vertical velocity is introduced at the lower boundary by the method described above. The numerical simulation has been carried out for the period of $2 \mathrm{~h}$ after the earthquake. At first, acoustic waves are produced near the surface, propagating up to the ionosphere-thermosphere region in several minutes. The calculated vertical velocities at 10, 30, and $60 \mathrm{~min}$ after the perturbation at the surface are shown as contour plots in Fig. 4(a)-(c), respectively. Numbers for the contours are logarithms of vertical speed in meters per second, and plus and minus signs indicate upward and downward motion, respectively. Solid and broken lines also indicate upward and downward motion, respectively. Contour lines for a speed of less than $1 \mathrm{~m} / \mathrm{s}$ are not shown. At 10 min after the initial perturbation, the acoustic waves reach the thermosphere, and the thermosphere starts to oscillate vertically at a speed of more than $100 \mathrm{~m} / \mathrm{s}$ (Fig. 4(a)). The disturbance then starts to spread out in the horizontal directions. It appears that the vertical wavelength is about $100 \mathrm{~km}$ in the region above the epicenter. At $30 \mathrm{~min}$, the front of the disturbance reaches a distance $1500 \mathrm{~km}$ from the epicenter (Fig. 4(b)). In the horizontal direction, wavelike structures with rather long wavelengths begin to form. The structure of the vertical velocity becomes complicated, probably because some waves are reflected and modified by the top of the thermosphere, where the molecular viscosity increases rapidly with altitude. Above the epicenter, the thermosphere continues to oscillate, although the amplitude becomes smaller. At $60 \mathrm{~min}$, the front of the disturbance reaches $2500 \mathrm{~km}$ away from the epicenter (Fig. 4(c)). A clear wave-like structure is seen in horizontal direction. The horizontal wavelength tends to become larger as the wave moves farther away from the epicenter.

Figure 5 shows the temporal variation in the calculated vertical velocities at an altitude of $120 \mathrm{~km}$ above the epicenter. An extremely large initial disturbance with a vertical speed of more than $100 \mathrm{~m} / \mathrm{s}$ is driven. After several oscillations, the amplitude of the vertical velocity rapidly decreases. The period of oscillation of the vertical velocity is about $4 \mathrm{~min}$. After the rapid decrease in the vertical oscillation, the amplitude increases again slightly after $25 \mathrm{~min}$, and then decreases after $40 \mathrm{~min}$. Figure 6 shows the power spectrum density of the vertical velocity at $120 \mathrm{~km}$ above the epicenter. Since the initial perturbation is extremely large and irregular, only the velocity data after $11 \mathrm{~min}$ are adopted in this analysis. It is clear that oscillations with periods of 3.8 and 4.6 min are dominant. A weaker oscillation with a $3.2-\mathrm{min}$ period is also seen.

The 3- to 5-min oscillations can be interpreted as acoustic waves trapped between the surface and the lower thermosphere. Walterscheid et al. (2003) studied acoustic waves in the mesosphere and thermosphere driven by intense deep convection in the troposphere using a nonhydrostatic compressible atmosphere model, which is similar to our model.
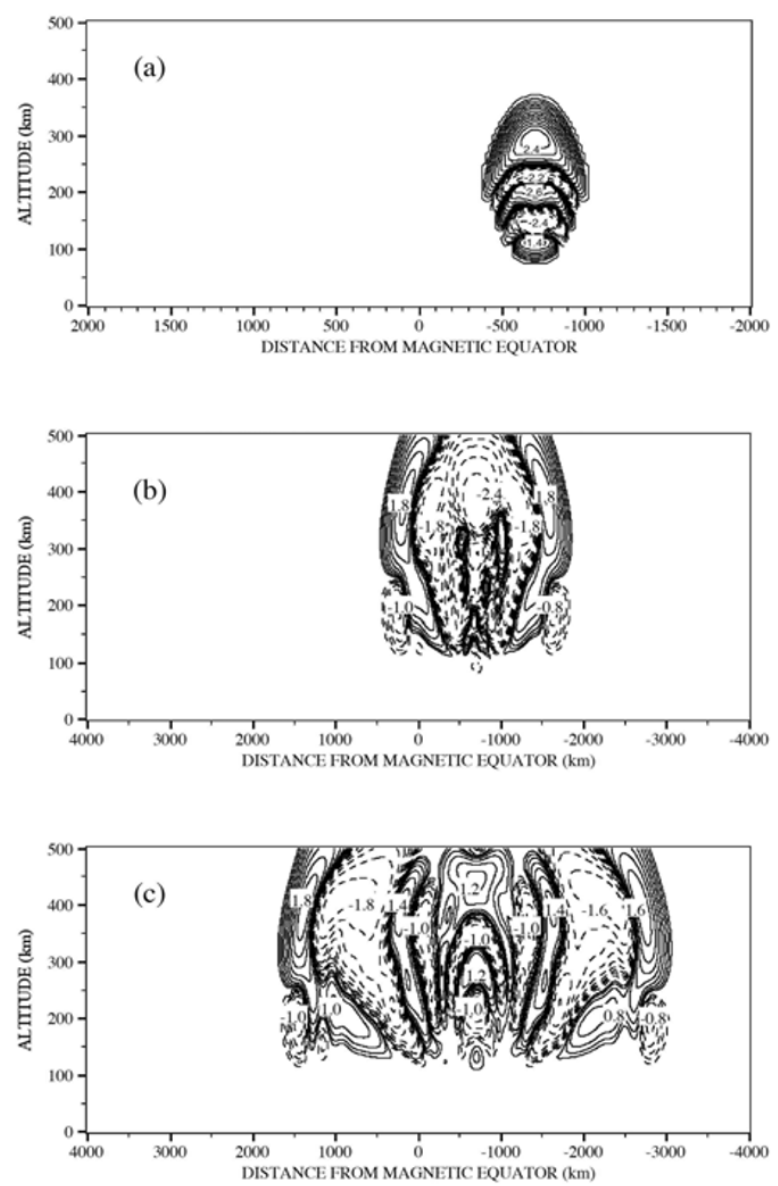

Fig. 4. Contour plot of the calculated vertical velocity at (a) $10 \mathrm{~min}$, (b) $30 \mathrm{~min}$, (c) $60 \mathrm{~min}$ after the onset of the earthquake. Numbers for contours are logarithms of vertical speed in meters per second, and plus and minus signs indicate upward and downward motion, respectively. The speed less than $1 \mathrm{~m} / \mathrm{s}$ is not shown. Solid lines and broken lines indicate upward and downward motion, respectively.

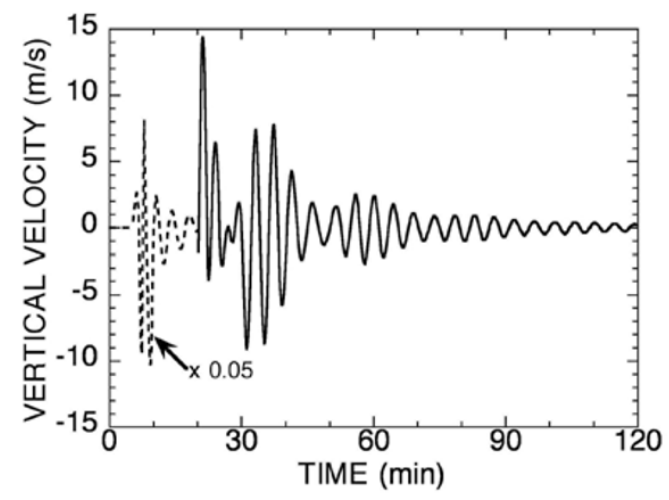

Fig. 5. Temporal variation in the calculated vertical velocity at altitude of $120 \mathrm{~km}$ just above the epicenter. Since the initial velocity is very large, the velocity values before $20 \mathrm{~min}$ are multiplied by 0.05 .

Their simulations revealed that major convective storms in the tropics launch acoustic waves into the mesosphere thermosphere directly above the storm centers. They found that the period interval of 3-5 min is a trapped oscillation. Figure 7 shows the altitude profile of the acoustic cutoff pe- 


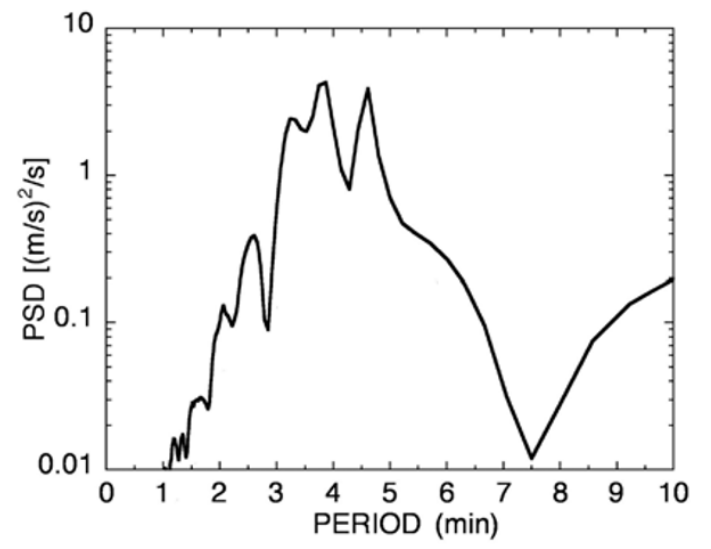

Fig. 6. Power spectrum density of the vertical velocity at $120 \mathrm{~km}$ above the epicenter. Since the initial perturbation is extremely large and irregular, only the velocity data after $11 \mathrm{~min}$ are used in this analysis. It is clear that oscillations with periods of 3.8 and 4.6 min are dominant. A weaker oscillation with a $3.2-\mathrm{min}$ period is also seen.

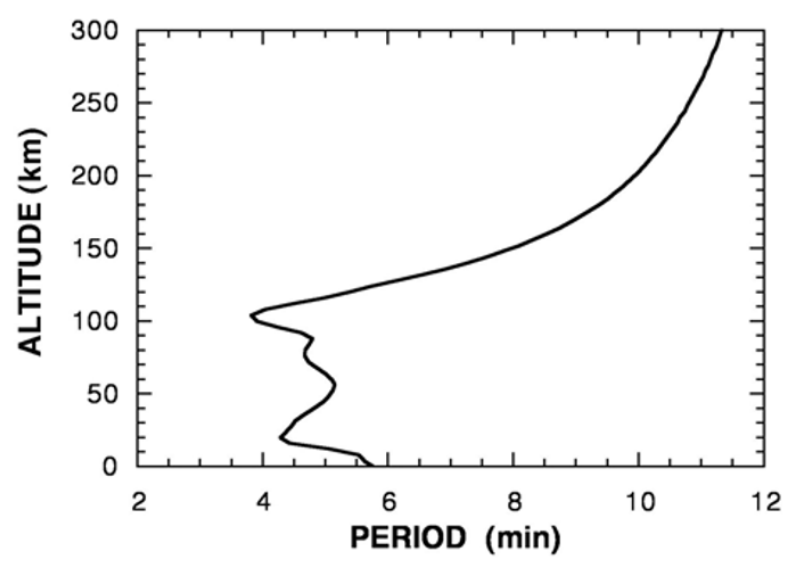

Fig. 7. Altitude profile of the acoustic cutoff period for the temperature profile in the model atmosphere used in the simulation.

riod for the non-isothermal temperature distribution used in our model. According to the theory, acoustic waves with a period shorter than 4 min can propagate freely up to the thermosphere. Waves with a period around $4 \mathrm{~min}$ are trapped between the lower thermosphere and the ground, while some portion of the wave can leak into the thermosphere. Waves with a period between 4 and 6 min can be trapped in the lower atmosphere, and those with a period longer than $6 \mathrm{~min}$ are evanescent. Therefore, it is expected that similar oscillation can also be generated by a sudden sea surface displacement.

Thermospheric winds, especially horizontal winds, play an important role in modifying the electron density profiles. The electron density in the $F$ region is mainly determined by the ion drift, which is given by ion-neutral drag force in the model. Figure 8(a) and (b) show contour plots of the horizontal neutral velocities at 30 and $60 \mathrm{~min}$, respectively, after the onset of the earthquake. Numbers for the contours are logarithms of horizontal speed in meters per second, and plus and minus signs indicate southward and northward, respectively. The front of the perturbed veloc-
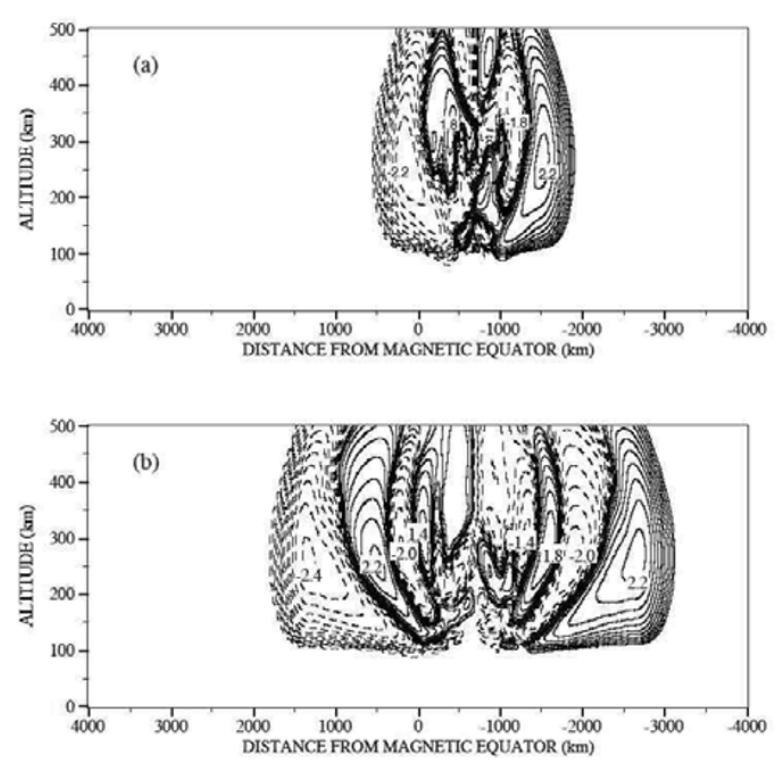

Fig. 8. Contours of the calculated horizontal velocity at (a) $30 \mathrm{~min}$, and (b) $60 \mathrm{~min}$ after the onset of the earthquake. The region between 4000 $\mathrm{km}$ north and south to the magnetic equator is shown. Numbers for contours are logarithms of horizontal speed in meters per second, and plus and minus signs indicate southward and northward, respectively. The speed less than $1 \mathrm{~m} / \mathrm{s}$ is not shown. Solid lines and broken lines indicate southward and northward, respectively.
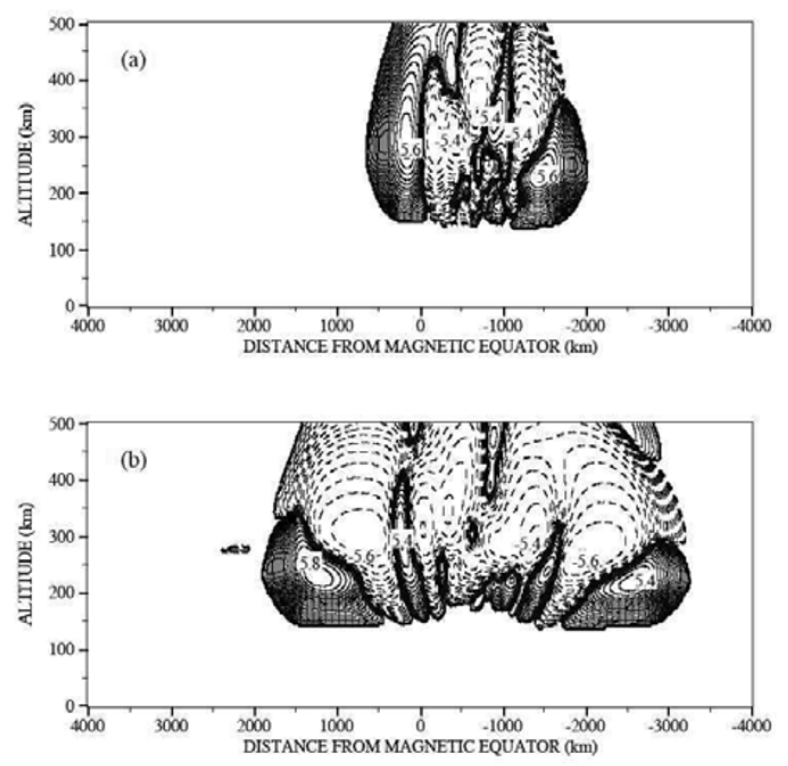

Fig. 9. Contours of the calculated electron density change from the initial electron density distribution at (a) $30 \mathrm{~min}$, and (b) $60 \mathrm{~min}$ after the onset of the earthquake. Numbers are in the unit of $\log \mathrm{cm}^{-3}$. Solid lines and broken lines indicate increase and decrease, respectively.

ity has a horizontal velocity away from the epicenter. That is, in the north of the epicenter, the front of the velocity is northward, and in the south of the epicenter, it is southward. The leading atmospheric waves propagate at a phase speed of $675 \mathrm{~m} / \mathrm{s}$. The wavelength of the horizontal velocity appears to become larger from a few hundreds of kilometers near the epicenter up to about $1000 \mathrm{~km}$. As 
discussed later, these waves appear to have the nature of the ducted (guided) thermospheric gravity waves proposed by Francis (1973, 1975). Starting with the initial steadystate ionosphere, the ionospheric variation caused by atmospheric disturbance is obtained by the model. Changes in the electron density from the initial electron density distribution at 30 and $60 \mathrm{~min}$ after the onset of the earthquake are shown in Fig. 9(a) and (b), respectively. At $30 \mathrm{~min}$, the regions of the enhanced horizontal neutral winds, which flow away from the epicenter, reach a distance of $1500 \mathrm{~km}$ from the epicenter (Fig. 8(a)). The electron density in the topside ionosphere increases in the front of the wave mainly through convergence of the horizontal neutral velocity. Behind the first horizontal wave packet, the electron density decreases due to the divergence of the horizontal velocity. A clear asymmetry of the electron density between the north and the south of the epicenter is seen. This is due to the effect of inclination of the magnetic field. This discussed in more detail in the next section.

\section{Discussion}

The numerical calculations have demonstrated that the atmospheric perturbation released by the sea surface displacement driven by the earthquake generates vertically propagating acoustic waves. Acoustic waves with periods of about 3-5 min induced by the sea surface displacement are considered to be trapped in a thermal duct in the mesosphere below an altitude of about $100-120 \mathrm{~km}$, and these have a standing wave character directly over the earthquake region. It was recognized in early studies that infrasonic waves with a period of 2-4 min are indeed generated by disturbance events near the surface, such as meteor bombardments (Whipple, 1930) and tropospheric convection or thunderstorms (Georges, 1973). The acoustic oscillations that are mainly confined to the tropospheremesosphere duct persist for about an hour (Walterscheid et al., 2003). Recent theoretical analyses with a realistic atmospheric temperature profile indicate that resonant waves with periods of $4.5,3.8$, and $3.2 \mathrm{~min}$ are known as the fundamental mode and the first and the second overtone modes, respectively (Kanamori and Mori, 1992; Kanamori et al., 1994; Lognonné et al., 1998; Nishida et al., 2000; Fukao et al., 2002). It is also known that some of the wave energy leaks into the upper thermosphere, producing oscillations with the same periods even in the entire thermosphere. In our simulation, these predominantly 3 - to 5-min waves are strongly driven for about $30 \mathrm{~min}$ after the earthquake, their amplitudes weakening with time thereafter (Fig. 5). For the inputs in the present calculation, the initial amplitude of the vertical velocity associated with excitation of a thermospheric acoustic disturbance is about $200 \mathrm{~m} / \mathrm{s}$ just above the epicenter, but this decreases rapidly with time. At about $30 \mathrm{~min}$, large-scale atmospheric waves begin to form in the thermosphere and propagate horizontally at a speed of 300$700 \mathrm{~m} / \mathrm{s}$, which is consistent with the speed of gravity waves found in previous observations and in theoretical studies as described in Section 4.4.

It must be noted that there are some limitations to the simulation model. First, our model does not include background neutral winds because background winds are not very important for the mainly vertically propagating acoustic waves of interest here. In the thermosphere, however, background winds become larger and should affect the propagation of the gravity waves. Second, the model is two-dimensional (altitude and latitude), in which all quantities are assumed to be uniform in the longitudinal direction. That is, the longitudinal extent of the surface displacement is assumed to be infinite, while the observed displacement of the sea surface occurred within a length of about $200 \mathrm{~km}$ in longitude. Therefore, the two-dimensional model would give larger perturbation in the region far from the epicenter. The three-dimensional effects also become important in the ionospheric calculation. In addition, longitudinal variations usually exist in the ionosphere, and ionospheric dynamo effects become important when the neutral atmosphere moves across the magnetic field lines. Third, the initial pressure perturbation of the atmosphere at the surface is introduced by giving a sudden vertical velocity at the lower boundary. This is not necessarily realistic because the vertical grid size of $2 \mathrm{~km}$ is far too large to express the real sea surface shape. At present, reducing the vertical grid size to a scale of the actual surface shape is practically impossible because of limitation to the computational power. Forth, in the Sumatra earthquake, the rupture of crust occurred in many segments successively from the $2^{\circ} \mathrm{N}$ to about $14^{\circ} \mathrm{N}$, although the first rupture appears to be largest.

There are other approximations and simplifications in the atmospheric and ionospheric model, as described earlier. Nonetheless, the overall agreement between the simulation results and the observed variations in the magnetic pulsations and in the electron densities seems to be fairly good, as shown in the next subsections. Variations of physical parameters obtained by the model are compared with data at various observational sites. Locations of the observational sites and the epicenter of the earthquake, which we referred to, are illustrated in the papers of Otsuka et al. (2006), Iyemori et al. (2005), and Heki et al. (2006).

\subsection{Comparison with magnetic pulsation data}

A long-period Pc5 pulsation was observed at Phimai in Thailand, shortly after the origin time of the Sumatra earthquake on December 26, 2004. Figure 10(a) is a plot of the filtered data of variations in the $H$ component of the magnetic field at Phimai taken from Iyemori et al. (2005), indicating that there was a localized long-period pulsation with a period about $4 \mathrm{~min}$ at Phimai. The oscillation appears to last for more than $1 \mathrm{~h}$. According to past numerical simulations with realistic atmospheric parameters and various acoustic wave sources in the lower atmosphere, oscillations with a period of 3-5 min tend to appear in the thermosphere as a result of energy input in the lower atmosphere, and these oscillations last for a rather long period. For example, simulations by Walterscheid et al. (2003) revealed that the wave lasts more than $30 \mathrm{~min}$ without forcing. It was also shown that a second wave packet appears in their simulation without a second source.

As for the magnetic field oscillation with a period of $3.6 \mathrm{~min}$, Iyemori et al. (2005) proposed an ionospheric dynamo mechanism in the ionospheric $E$ region at an altitude of $100-120 \mathrm{~km}$ over the epicenter generated by a vertical wind oscillation caused by the atmospheric duct resonance 

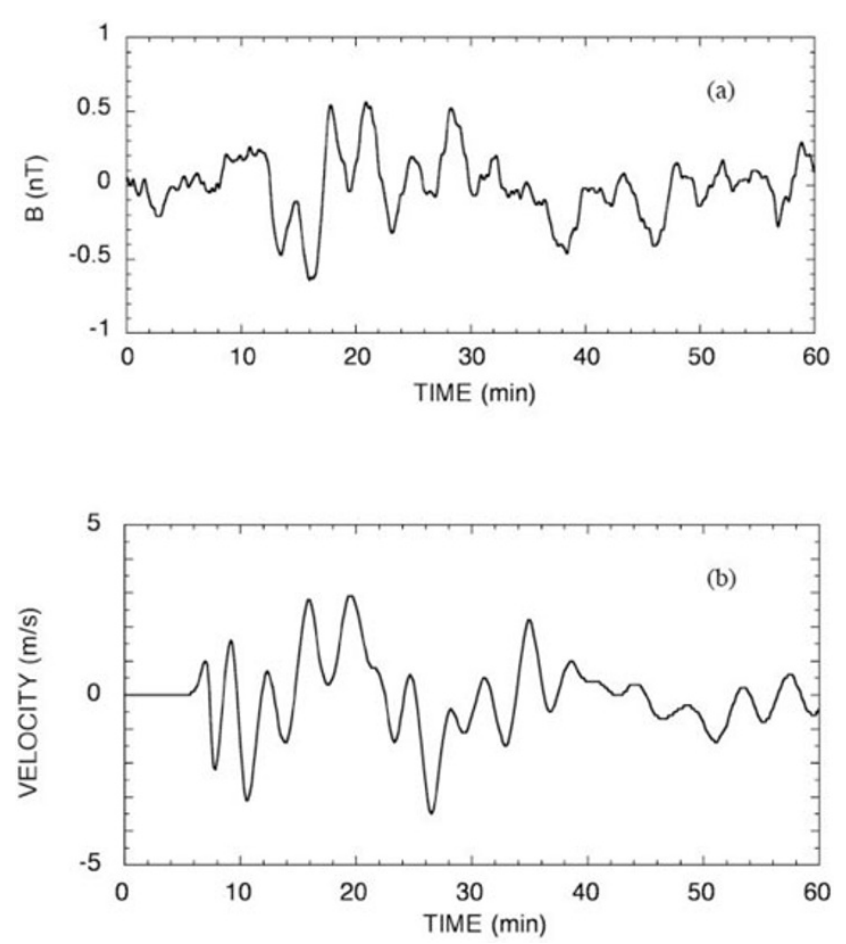

Fig. 10. (a) Filtered $H$-component magnetic field data at Phimai (PHI) for December 26, 2004 from 0100 UT to 0200 UT (Iyemori et al., 2005). (b) Calculated vertical velocity at an altitude of $120 \mathrm{~km}$ and at $200 \mathrm{~km}$ south from the epicenter. Oscillation patterns of these two quantities appear to be quite similar to each other.

set up by the earthquake. That is, at the commencement of the earthquake, a wide area at the epicenter suddenly lifted up or depressed, and an atmospheric pressure variation propagated upward as an acoustic wave. Part of the acoustic wave was reflected back to the lower thermosphere, forming a duct resonance, resulting in a vertical oscillation of the atmosphere having a resonance frequency of $3.6 \mathrm{~min}$ in the ionospheric $E$ region, which generates the dynamo current there. The time lag of $12 \mathrm{~min}$ is consistent with the time necessary for an acoustic wave to travel from ground to the ionosphere.

The geomagnetic latitudes at the epicenter and at Phimai are almost the same, that is, they are about $7^{\circ}$ south and north from the geomagnetic equator, respectively. These analyses strongly suggest that the vertical wind is indeed induced near the epicenter and is approximately proportional to the magnetic field variation. Therefore, we compare the simulated variation of vertical wind and the observed magnetic field variation. Since there is a several-degree difference in magnetic longitude between Phimai and the epicenter, the vertical velocity at an altitude of $120 \mathrm{~km}$ and $200 \mathrm{~km}$ away from the epicenter is chosen.

The temporal variation in the calculated vertical neutral velocity at the point is shown in Fig. 10(b). Since the point is away from the epicenter, the initial oscillation is not as large as the velocity just above the epicenter. It is interesting to see that the calculated oscillation pattern of the vertical velocity is quite similar to the magnetic field variation at Phimai. The amplitudes of the oscillation in the magnetic field and in the velocity become larger at about
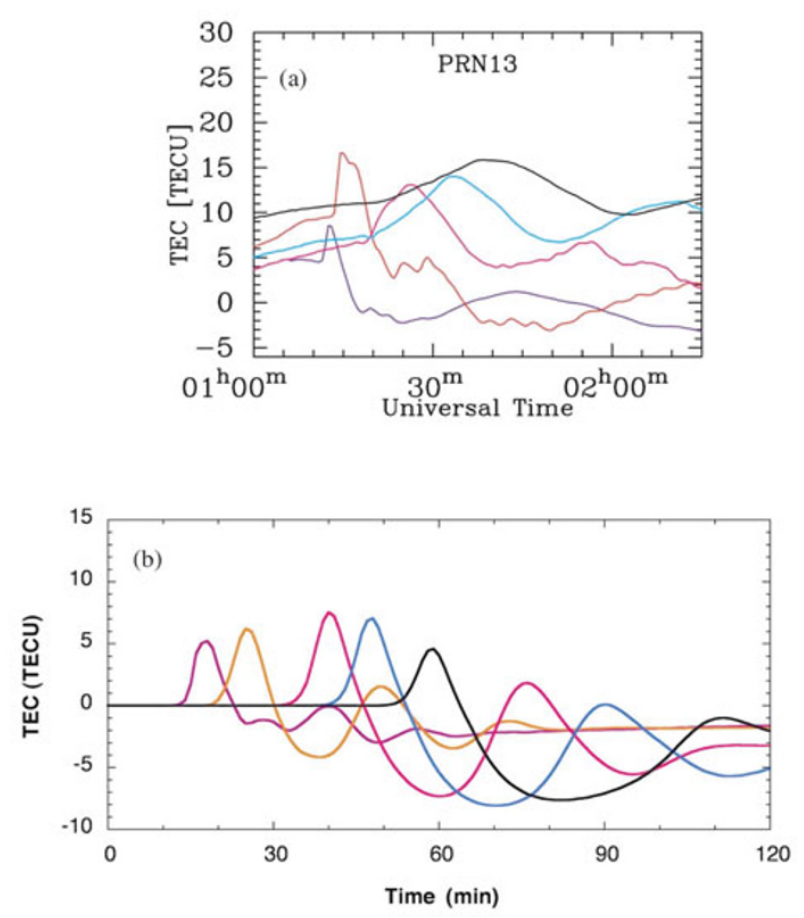

Fig. 11. (a) Observed GPS/TEC time variations at the ionospheric points corresponding to Padang (purple line), Medan (orange line), Chumphon (red line), Chiang Mai (blue line), and Bangkok (black line). (b) Temporal variations in the calculated height-integrated electron density near the GPS/TEC observation points of (a). Colors of the lines correspond to locations indicated by colors in (a).

$20 \mathrm{~min}$, decrease at about $30 \mathrm{~min}$, increase again at $35 \mathrm{~min}$, then decrease gradually. This is likely to be caused by the resonance of waves with a few different periods (Fig. 6). The agreement of the magnetic field variation and the velocity variation suggests that the neutral motion generated near the epicenter drives the oscillatory electric field in the ionosphere, as proposed by Iyemori et al. (2005).

\subsection{Comparison with GPS/TEC data}

Otsuka et al. (2006) reported that TEC enhancements of 1.6-6.9 TECU were observed at sub-ionospheric points located 360-2000 km north of the epicenter, and the TEC enhancements were moving northward from the epicenter. Figure 11(a) shows one of the observed variations of the slant TEC obtained by the five GPS receivers. A clear increase in TEC was observed along the ray paths from the PRN13 satellite to the five sites. The increase was first observed at Padang, and then successively at Medan, Chumphon, Bangkok, and Chiang Mai; the TEC perturbations occurred at the sub-ionospheric points at horizontal distances of $380,670,1270,1570$, and $2030 \mathrm{~km}$ away from the epicenter, respectively.

Figure 11(b) shows the temporal change in the heightintegrated electron densities calculated by our model. The electron density variations at points corresponding to the above observation points are plotted for comparison. The increase in the calculated vertical TEC at "Padan" occurred at about $13 \mathrm{~min}$ after the earthquake and reaches the maximum at about $18 \mathrm{~min}$. The increase is about 5 TECU. The 
TEC then decreases and oscillates several times. The relatively clear second maximum appears at $40 \mathrm{~min}$. The rise time of the model is somewhat slower than the observed TEC, but the overall behavior is quite similar to that of the observation. At "Medan", the calculated TEC starts to increase at $18 \mathrm{~min}$, while the observed TEC starts to increase at $14 \mathrm{~min}$. The TEC decreases and oscillates a few times. At the other points, observed TEC enhancements tend to start earlier than those of the model, indicating that the phase speed of the TID (traveling ionospheric disturbance) in the model is slower than the observed speed.

In addition to the difference in the phase speed, the temporal variations in the observed TECs at large distances tend to have broader peaks than the calculated TECs. It appears that the front of the increase of TEC propagates much faster that the acoustic speed. Otsuka et al. (2006) suggested that in the Sumatra earthquake event, the rupture of the sea floor occurred sequentially at multiple points from the south to the north and that the wave source would propagate northward at the almost same velocity as the rupture. The acoustic waves excited during the rupture propagation reach ionospheric altitudes much earlier than the waves excited at the epicenter because of the faster movement of the rupture region. It is also noted that the observed TECs appear to have high-frequency components (the order of minutes), which are likely to be generated by high-frequency acoustic waves. Similar kinds of oscillations are also present in the simulated TECs, but the amplitude is so small that the oscillations are not seen in Fig. 11(b).

Figure 12(a) illustrates the temporal variations in the TECs calculated by our numerical model in the TEC unit. The vertical axis is the time after the onset of the earthquake, and the horizontal axis is the horizontal distance from the magnetic equator. The TEC starts to change at about 10 min near the epicenter. The then enhanced TECs propagate horizontally, but the increase in the northern side of the epicenter is much larger than that in the southern side. Phase velocity of the peak of the TID change is about $675 \mathrm{~m} / \mathrm{s}$ for the model, while it is $730 \mathrm{~m} / \mathrm{s}$ for the observations (Otsuka et al., 2006). The difference is probably caused by the difference in the thermospheric temperature of the background atmosphere as well as the horizontal background velocity in the thermosphere. The TEC enhancement is followed by the larger depletion, which is mainly caused by the divergence of the horizontal velocity. After the first wave, the second TID appears to be created. The phase speed is about $350 \mathrm{~m} / \mathrm{s}$ and is significantly slower than the first TID. These TIDs are interpreted to be the ducted thermospheric mode gravity wave, which is driven by the sudden pressure impulse. According to Francis $(1973,1975)$, waves with high-phase velocities $(600-$ $700 \mathrm{~m} / \mathrm{s}$ ) are the ducted thermospheric mode gravity waves, not the acoustic waves. Waves with slower phase speeds are also possible. It is not clear whether or not the slower gravity waves obtained by the simulation are those slower mode waves.

Although the atmospheric perturbation associated with the initial sea surface displacement explains most of the TID behaviors, the speed of the wave front of the TIDs reaches about $2000 \mathrm{~m} / \mathrm{s}$, which is faster than the sonic speed, this
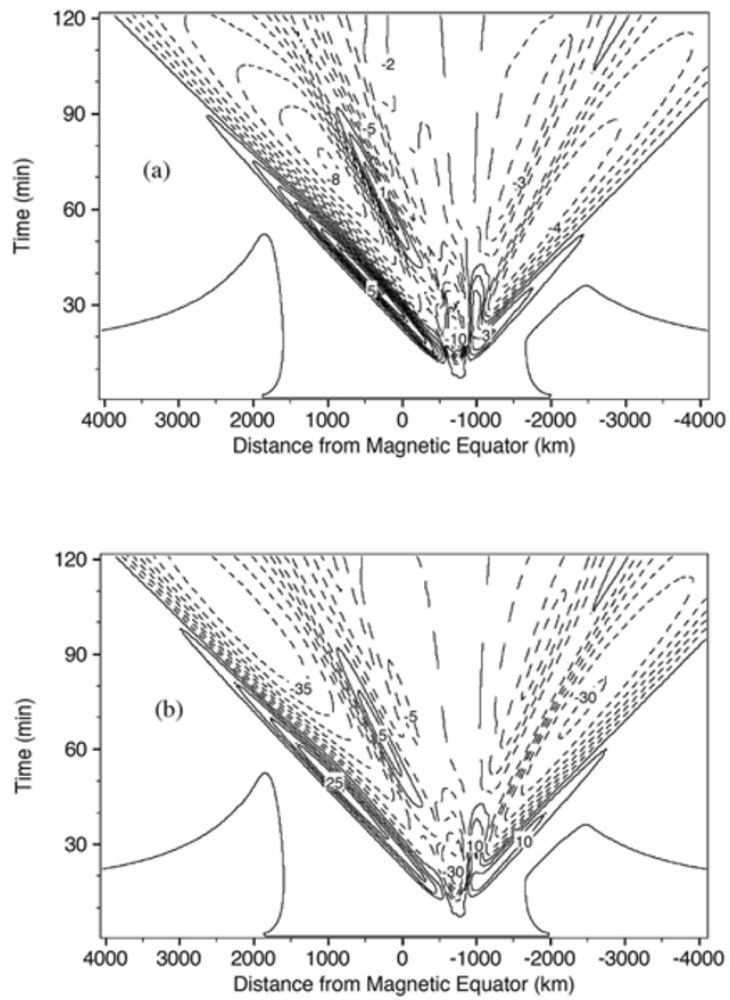

Fig. 12. (a) Two-dimensional plot of the change in the vertical TEC in the unit of TECU $\left(1\right.$ TECU $\left.=10^{16} \mathrm{~m}^{-2}\right)$ obtained by the model. The vertical axis is time after the onset of the earthquake, and the horizontal axis is the latitudinal distance from the magnetic equator. Solid contours indicate an increase of TEC, and broken lines indicate a decrease. The initial TEC enhanced regions propagate at a speed of $675 \mathrm{~m} / \mathrm{s}$ in both the northward and southward directions, but the increase is significantly larger in the north of the epicenter. The second waves travel at a speed of about $350 \mathrm{~m} / \mathrm{s}$. There is a clear asymmetry of TEC with respect to the epicenter. (b) Same as (a), but the relative change with respect to the initial TEC in percentage is shown. The north-south asymmetry of TEC is seen even in the relative change in the electron density with respect to the background electron density.

cannot be explained by the propagation of acoustic-gravity waves. It is likely that acoustic waves are generated at the multiple point sources, which move sequentially from south to north (Otsuka et al., 2006; Heki et al., 2006).

Otsuka et al. (2006) also showed that there is a clear asymmetry of the TEC change between the north and the south of the epicenter. In the south of the epicenter, TEC enhancement was only 0.6 TECU, and no TEC enhancements were seen east of the epicenter. These authors suggested that this directivity of the TEC variations with respect to the azimuth from the epicenter could be caused partially by the directivity in the response of the electron density variation to the acoustic waves in the neutral atmosphere. However, their proposal does not fully explain the TEC asymmetry in the region far from the epicenter, where magnetic dip angles are different between the north and south of the epicenter. In our simulation, the north-south asymmetry of TEC change clearly appears in Fig. 12(a); TEC enhancement is larger to the north and smaller to the south of the epicenter. This is partially due to the initial electron density distribution, which has larger TEC north of the epicenter and smaller 


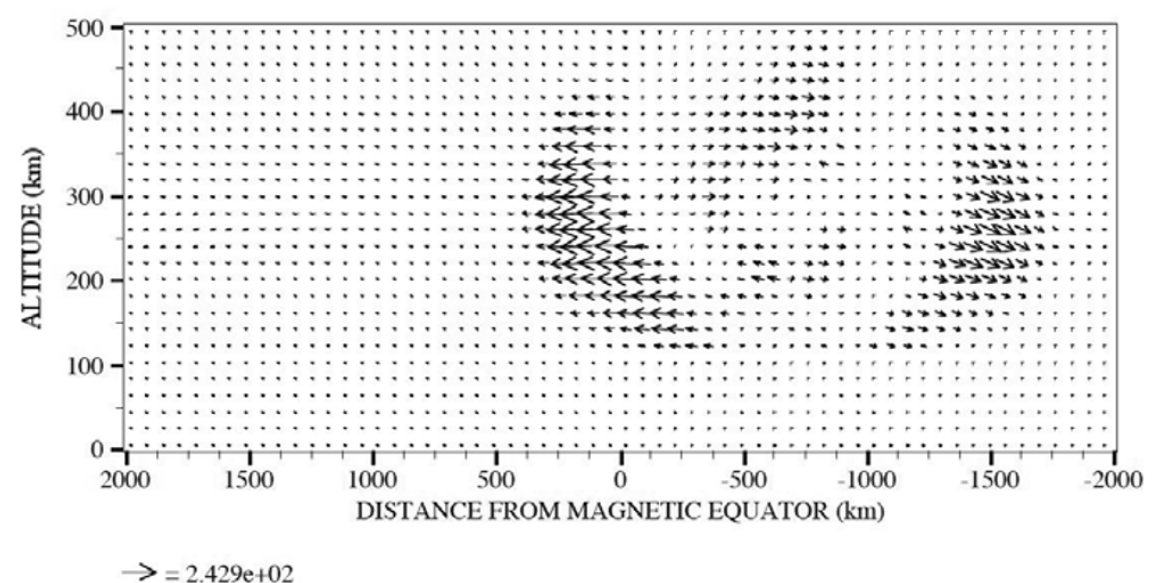

Fig. 13. Velocity vectors of ions at $30 \mathrm{~min}$ after the onset of the earthquake. The maximum arrow length is $243 \mathrm{~m} / \mathrm{s}$. Ion drift is mainly driven by the horizontal neutral wind through ion-neutral collisions. South of the epicenter, ions tend to move downward because magnetic field lines have larger dip angles than those north of the epicenter.

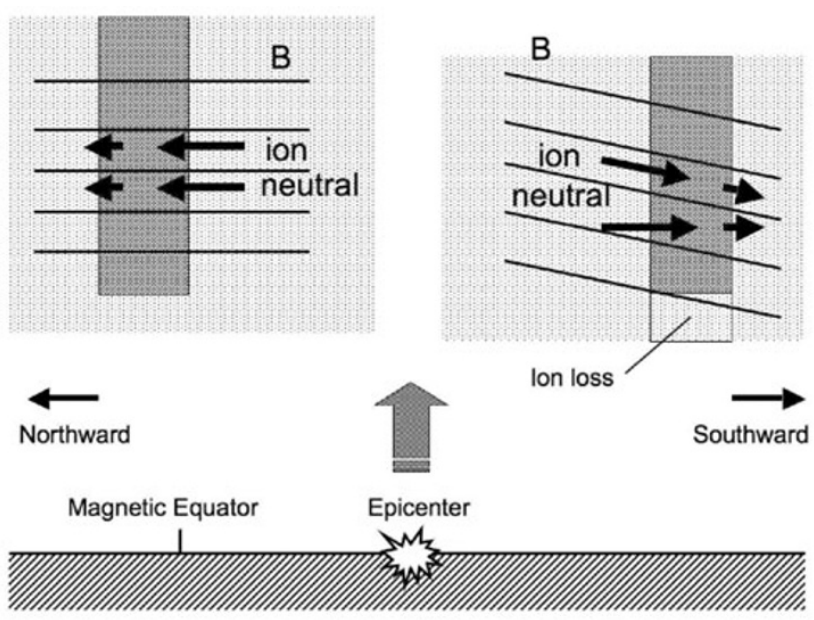

Fig. 14. Schematic picture of the mechanism of the north-south asymmetry of the electron density change. North of the epicenter, the magnetic field lines are nearly horizontal, and the ion motion is almost the same as horizontal neutral motion, leading to compression in the wave front of the gravity wave. South of the epicenter, the magnetic field has larger dip angle, and the ions are forced to move to lower altitudes, where ions are lost more rapidly through ion-neutral chemistry.

TEC south. In order to see the asymmetry impartially, a relative change of TEC with respect to the initial TEC is plotted in Fig. 12(b). The asymmetry of TEC still exists, and the initial TEC variation is significantly larger north of the epicenter, although after $1 \mathrm{~h}$ the asymmetry becomes less significant.

Figure 13 shows the velocity vectors of ions at $30 \mathrm{~min}$. There is a clear difference in ion velocity directions between north and south of the epicenter. Since the magnetic field is nearly horizontal in the equator region, the ion motion is nearly horizontal. South of the epicenter, the magnetic dip angle is larger, and the ions move downward. Figure 14 schematically illustrates the mechanism of the electron density change. North of the epicenter, the electron density increases through compression of the ions, which is generated by the horizontal neutral drag force. South of the epicenter, similar compression occurs, but the ion compression is somewhat smaller because only a magnetic field line component of the neutral wind contributes the ion motion and because the lower part of the enhanced density region is lost by ion loss which is dominant in the $E$ region. This ion loss rate is always larger south of the epicenter. Otsuka et al. (2006) reported that no TEC change was observed in the east of the epicenter. This can be interpreted by the fact that ion motion is not affected by the horizontal neutral wind perpendicular to the magnetic field lines.

\subsection{Comparison with ionosonde data}

Significant variations in the ionosphere after the earthquake were also detected by the ionosondes at Chumphon $\left(10.7^{\circ} \mathrm{N}, 99.4^{\circ} \mathrm{E}\right.$, dip latitude $\left.=+3.22^{\circ}\right)$ and at Chiang Mai $\left(18.8^{\circ} \mathrm{N}, 98.9^{\circ} \mathrm{E}\right.$, dip latitude $\left.=+13.21^{\circ}\right)$. Figure $15(\mathrm{a})-$ (d) show the variations of $f_{o} F_{2}$ and $h_{m} F_{2}$ manually scaled every $5 \mathrm{~min}$ at the two observation sites (broken lines). In order to extract the earthquake-related variations from the data, we use deviations from the median values taken from 14-day data between 1 week before and 1 week after the earthquake. The solid lines indicate the calculated variations at the points approximately corresponding to the two observation sites. In the plots of Fig. 15, the zero levels of the simulation results are arbitrarily chosen so that the calculated values can be compared well with the observed values. The actual values of the zero levels in the simulation results are: 11 and $8 \mathrm{MHz}$ for $f_{o} F_{2}$ at Chumphon and at Chiang Mai, respectively, and 320 and $280 \mathrm{~km}$ for $h_{m} F_{2}$ at Chumphon and at Chiang Mai, respectively.

In $f_{o} F_{2}$ at Chumphon, the first enhancement occurred at 20-30 min after the earthquake, and another weak enhancement occurred at around $50 \mathrm{~min}$. The calculated enhancement occurred at $30 \mathrm{~min}$ and at about $60 \mathrm{~min}$, which are a little later than the observed times. This is probably because the phase speed of the gravity wave in the model is slower than the observed gravity waves, as mentioned in the previous section. The same tendency is also seen in the $f_{o} F_{2}$ at Chiang Mai (Fig. 15(c)). The initial enhancement of $f_{o} F_{2}$ appears at about $40 \mathrm{~min}$, while the enhancement occurs at about $50 \mathrm{~min}$ in the model. 
The observed $h_{m} F_{2}$ at Chumphon is rather complicated, and difficult to compare with the calculated values. The observed $h_{m} F_{2}$ at Chiang Mai has two peaks: one at about 20-30 min, and another enhancement at 70-80 min, while the calculated $h_{m} F_{2}$ has minimum at 50-65 min and a broad peak at $65-85 \mathrm{~min}$. Although the shape of the variation is different, the overall variations are similar. It is noted that the ionosphere exhibits larger variations at Chiang Mai than at Chumphon despite Chiang Mai being farther than Chumphon from the epicenter. The simulation result suggests that this is partly because the thermospheric gravity wave is not fully developed at Chumphon and more developed at Chiang Mai and partly because the magnetic dip angle is larger at Chiang Mai, resulting in larger vertical motion of the ionosphere than that at Chumphon.

\subsection{Comparison with previous studies}

There have been a number of studies on acoustic-gravity waves in the upper atmosphere that originated from local disturbances in the lower atmosphere. One of the most famous ionospheric events associated with earthquakes is the Alaska Earthquake, which occurred at 0336 UT on March 28, 1964. A large ionospheric variation was detected by ionosondes in College and Adak, Alaska, Palo Alto, California, and Maui, Hawaii, as well as by high-frequency Doppler records in Boulder, Colorado (Leonard and Barnes, 1965; Davies and Baker, 1965). The data showed two different types of disturbances: (1) traveling ionospheric disturbances at a speed of about $400 \mathrm{~m} / \mathrm{s}$, and (2) those at a speed of about $2 \mathrm{~km} / \mathrm{s}$. The former is considered to be gravity waves generated by the impulsive atmospheric perturbation propagated from the epicenter, while the latter is consistent with the speed of seismic surface waves, suggesting that the ionospheric disturbance originated from the ground just beneath the perturbed ionosphere. The result basically agrees with the result of the TIDs observed after the Sumatra earthquake, as described earlier (Otsuka et al., 2006).

Another unusual ionospheric event associated with an earthquake was detected over Chatanika, Alaska on April 12, 1978, using the Chatanika Incoherent Scatter Radar (Kelly et al., 1985). Large vertical oscillations with a speed of about $100 \mathrm{~m} / \mathrm{s}$ at high altitudes were observed. The oscillation had a period of $1-2 \mathrm{~h}$, and lasted for several hours. In our simulation, on the other hand, the large vertical motion of more than $100 \mathrm{~m} / \mathrm{s}$ appeared near the epicenter, but it lasted only for about $20 \mathrm{~min}$. The amplitude of the oscillation decreased rather rapidly with time in the model. It is not clear from our simulation why such a large oscillation of the upper atmosphere could be maintained for a long time after the Alaska earthquake. Kelly et al. (1985) also pointed out that viscous heating might play an important role in heating the upper thermosphere in this event, which might cause large vertical velocities. The viscous heating is not included in our simulation, and the effect needs to be considered in future studies.

Ionospheric perturbations related to volcanic eruptions have been observed several times. Among the events, the ionospheric disturbances following the eruption of Mount St. Helens on May 18, 1980 have been investigated extensively. In this event, it was found that the observed surface pressure perturbations and ionospheric perturbations could
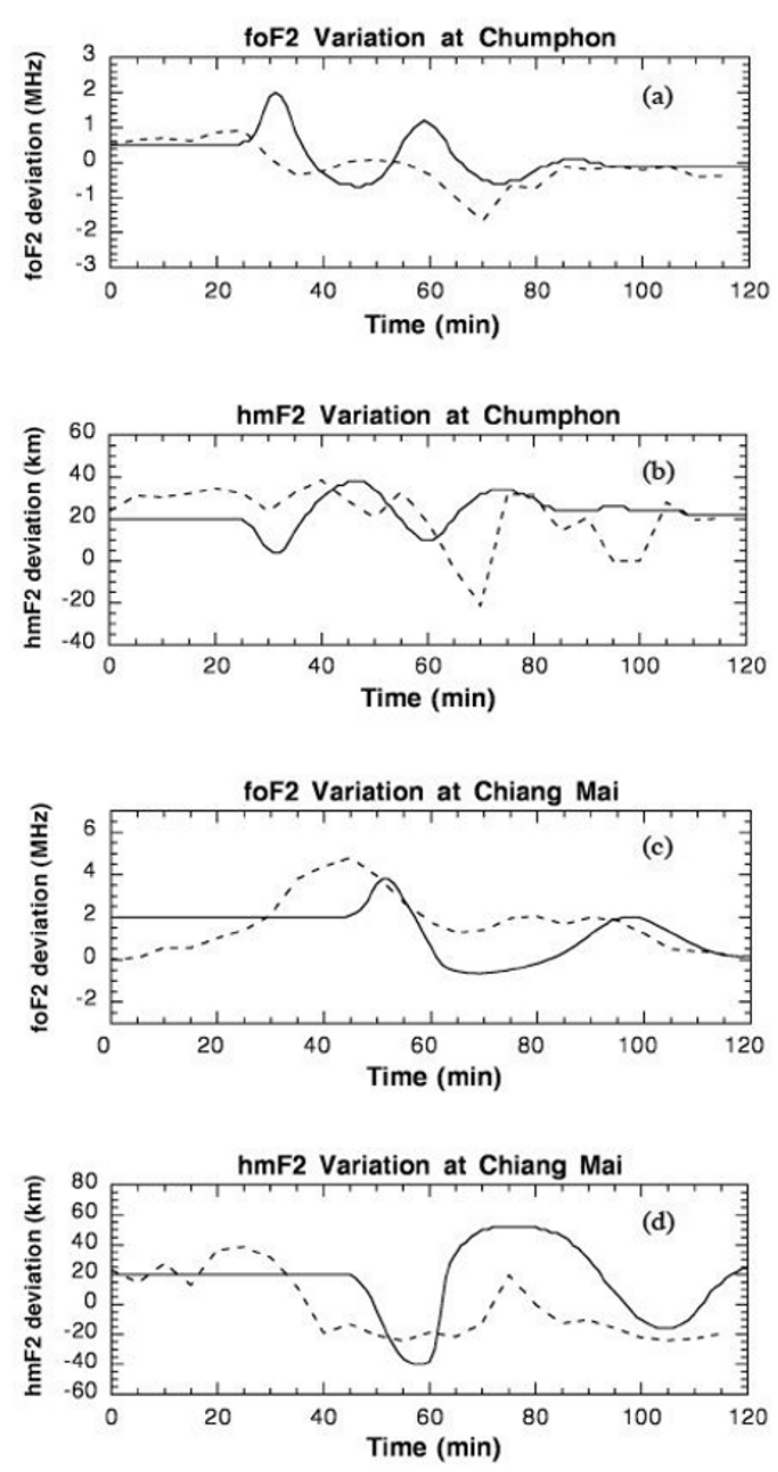

Fig. 15. Comparisons of the calculated values (solid lines) and observed values (broken lines) of $f_{o} F_{2}$ and $h_{m} F_{2}$. Observed data are obtained by ionosondes. (a) $f_{o} F_{2}$ variation at Chumphon, (b) $h_{m} F_{2}$ variation at Chumphon, (c) $f_{o} F_{2}$ variation at Chiang Mai, and (d) $h_{m} F_{2}$ variation at Chiang Mai.

be explained by propagation of Lamb modes with a horizontal propagation velocity of slightly above $300 \mathrm{~m} / \mathrm{s}$, i.e., the sonic speed (Liu et al., 1982). At a large distance, however, the velocity reaches about $500 \mathrm{~m} / \mathrm{s}$, suggesting that waves with gravity modes were also generated (Roberts $e t$ al., 1982).

Ionospheric disturbances with propagation speeds of several hundreds meters per second were also seen over a range of distances associated with nuclear tests in the early 1960s (cf. Francis, 1975). The disturbance fronts of the TIDs propagate at a speed of $600-700 \mathrm{~m} / \mathrm{s}$ in most cases, which is consistent with the TIDs observed in the Sumatra earthquake event. However, the waves with the Lamb modes were not clearly seen both in the observations and in our calculations of the Sumatra earthquake. This is probably because the displacement of the surface occurred simulta- 
neously in the extensive areas, which produced plane waves propagating upward with smaller horizontal expansion of the air.

Comprehensive reviews on various observations and theoretical studies are given in several papers (Row, 1967; Liu and Yeh, 1971; Francis, 1975; Blanc, 1985). Liu and Yeh (1971) analyzed the effect of a point source disturbance on the atmosphere. A very complete description is given for the linear response of an isothermal dissipationless plane atmosphere to an impulsive point source of momentum or heat. Their calculations predict the excitation of three distinct wave trains: (1) a high-frequency component with $\omega>\omega_{a}$ (acoustic waves), (2) an intermediate-frequency component with $\omega_{a}>\omega>\omega_{b}$ (buoyancy waves), and (3) a low-frequency component with $\omega_{b}>\omega$ (gravity waves), where $\omega_{a}$ and $\omega_{b}$ are the acoustic cut-off frequency and the Brunt-Väisälä frequency, respectively. At large distances and times, the disturbance is dominated by the gravity mode contribution with some contribution from the acoustic mode. The amplitude-distance relationship for gravity waves in an isothermal atmosphere depends on the nature of the exciting perturbation.

The calculations in our study and the observations of the Sumatra earthquake are qualitatively consistent with the result of Liu and Yeh (1971), except that the acoustic component decreases rather rapidly with distance in our study and the buoyancy component is not clear. Since the actual atmosphere has the rigid surface, temperature variations, heat conduction, and viscosity in the thermosphere, and ion-drag force, the behavior of acoustic-gravity is likely to be more complicated than suggested by the study of Liu and Yeh (1971).

Francis (1975) calculated in detail the properties of the ducted gravity modes using a realistic atmosphere with temperature variation and molecular viscosity. The ducted gravity waves were found to be able to propagate in the thermosphere and to carry significant energy at ionospheric heights. The fundamental mode $F$ in Francis' study has a group velocity that peaks at $\sim 700 \mathrm{~m} / \mathrm{s}$ with a period of 20 min; the second mode $G_{1}$ peaks at $500 \mathrm{~m} / \mathrm{s}$; the third mode $G_{2}$ peaks at $390 \mathrm{~m} / \mathrm{s}$. The speed of the front wave in our simulation as well as in the TEC observation agrees with the $F$ mode wave. The $F$ mode is consistent with the front wave in the simulation, which has a speed of $675 \mathrm{~m} / \mathrm{s}$. However, the second wave in the model has a speed of $350 \mathrm{~m} / \mathrm{s}$, which is closer to that of $G_{2}$ mode wave rather than that of $G_{1}$ mode. It is not clear why the $G_{1}$ mode is insignificant in the result of the present simulation. Since the present simulation model is specifically designed for the Sumatra earthquake conditions, separate numerical studies with more idealized conditions are necessary in order to quantitatively compare results of numerical calculations with theoretical studies.

\section{Summary}

A two-dimensional nonhydrostatic compressible atmosphere-ionosphere model was used to study the variations in the upper atmosphere associated with the displacement of the sea surface during the Sumatra earthquake. The calculated oscillation pattern in the lower thermosphere above the epicenter is consistent with unusual magnetic pulsation with a period of about $4 \mathrm{~min}$, which was observed $12 \mathrm{~min}$ after the origin time, suggesting that the ionospheric dynamo is likely to be caused by acoustic waves generated by the sea surface displacement (Iyemori et al., 2005). The result of the numerical simulation implies that atmospheric oscillation with a period of about $4 \mathrm{~min}$ can indeed be generated in the thermosphere.

The calculated ionospheric variations are also compared with various observations at Indonesia and Thailand. Variations in TEC, $f_{o} F_{2}$ and $h_{m} F_{2}$ were found to be in fairly good agreement with the simulation results. TIDs with a period of a few tens of minutes and a phase speed of several hundreds of meters per second are reproduced approximately. The observed TIDs are in reasonably good agreement with the ducted thermospheric gravity waves proposed by previously studies (e.g., Francis, 1975). It is suggested that the gravity waves are generated by a sudden pressure pulse propagated from the lower atmosphere. The comparison of the observations and simulation results indicates that a series of the ionospheric and magnetic variations observed by various instruments are certainly related to the earthquakeexcited atmospheric waves.

The two-dimensional atmosphere-ionosphere is successful in reproducing and interpreting various phenomena in the upper atmosphere, and coupled modeling of the atmosphere and ionosphere can be a useful tool in studying the effects of surface disturbances on the upper atmosphere. However, the actual sea surface displacement is spatially localized in the longitudinal direction and, therefore, a twodimensional approximation is not necessarily appropriate. A three-dimensional model with more realistic parameters of the surface perturbation, magnetic field model, background atmosphere-ionosphere model, and neutral winds is necessary in order to investigate the relationship between the surface disturbance and the upper atmospheric phenomena in more detail.

Acknowledgments. This work was supported by a Grant-in-Aid from the Ministry of Education, Culture, Sports, Science and Technology of Japan (No. 16654075). A part of the numerical simulation was performed using the computing facilities of the SolarTerrestrial Environment Laboratory and the Information Technology Center, Nagoya University. The ionosonde data were obtained in collaboration with Chiang Mai University, Thailand, and King Mongkut's Institute of Technology Ladkrabang (KMITL), Thailand.

\section{References}

Banks, P. M. and G. Kockarts, Aeronomy, Academic Press, New York, 1973.

Bilham, R., A flying start, then a slow slip, Science, 308, 1126-1127, 2005. Blanc, E., Observations in the upper atmosphere of infrasonic waves from natural or artificial sources: A summary, Ann. Geophys., 19, 395-409, 1985.

DasGupta, A., A. Das, D. Hui, K. K. Bandyopadhyay, and M. R. Sivaraman, Ionospheric perturbations observed by the GPS following the December 26th, 2004 Sumatra-Andaman earthquake, Earth Planets Space, 58, 167-172, 2006.

Davies, K. and D. M. Baker, Ionospheric effects observed around the time of the Alaskan earthquake of March 28, 1964, J. Geophys. Res., 70, 2251-2253, 1965.

Davies, J. B. and C. B. Archambeau, Modeling of atmospheric and ionospheric disturbances from shallow seismic sources, Phys. Earth Planet. Int., 105, 183-199, 1998. 
Francis, S. H., Acoustic-gravity modes and large-scale traveling ionospheric disturbances of a realistic, dissipative atmosphere, J. Geophys. Res., 78, 2278-2301, 1973.

Francis, S. H., Global propagation of atmospheric gravity waves: A review, J. Atmos. Terr. Phys., 37, 1011-1054, 1975.

Fukao, Y., K. Nishida, N. Suda, K. Nawa, and N. Kobayashi, A theory of the Earth's background free oscillation, J. Geophys. Res., 107, B9, 2206, doi:10.1029/2001JB000153, 2002.

Georges, T. M., Infrasound from convective storms: Examining the evidence, Rev. Geophys. Space Phys., 11, 571-594, 1973.

Hedin, A. E., Extension of the MSIS thermosphere model into the middle and lower atmosphere, J. Geophys. Res., 96, 1159-1172, 1991.

Heki, K. and J. Ping, Directivity and apparent velocity of the coseismic traveling ionospheric disturbances observed with a dense GPS array, Earth Planet. Sci. Lett., 236, 845-855, 2005.

Heki, K., Y. Otsuka, N. Choosakul, N. Hemmakorn, T. Komolmis, and T. Maruyama, Detection of ruptures of Andaman fault segments in the 2004 great Sumatra earthquake with coseismic ionospheric disturbances, J. Geophys. Res., 111, B09313, doi:10.1029/2005JB004202, 2006.

Hickey, M. P., G. Schubert, and R. L. Walterscheid, Acoustic wave heating of the thermosphere, J. Geophys. Res., 106, 1-6, 2001.

Hines, C. O., Internal atmospheric gravity waves at ionospheric heights, Can. J. Phys., 38, 1441-1481, 1960.

Hirata, K., K. Satake, Y. Tanioka, T. Kuragano, Y. Hasegawa, Y. Hayashi, and N. Hamada, The 2004 Indian Ocean tsunami: Tsunami source model from satellite altimetry, Earth Planets Space, 58, 195-201, 2006.

Igarashi, K., S. Kainuma, I. Nishimura, S. Okamoto, H. Kuroiwa, T. Tanaka, and T. Ogawa, Ionospheric and atmospheric disturbances around Japan caused by the eruption of Mount Pinatubo on 15 June 1991, J. Atmos. Terr. Phys., 56, 1227-1234, 1994.

Iyemori, T., M. Nose, D. Han, Y. Gao, M. Hashizume, N. Choosakul, H. Shinagawa, Y. Tanaka, M. Utsugi, A. Saito, H. McCreadie, Y. Odagi, and F. Yang, Geomagnetic pulsations caused by the Sumatra earthquake on December 26, 2004, Geophys. Res. Lett., 32, L20807, doi:10.1029/2005GL024083, 2005.

Kanamori, H. and J. Mori, Harmonic excitation of mantle Rayleigh waves by the 1991 eruption of Mount Pinatubo, Philippines, Geophys. Res. Lett., 19, 721-724, 1992.

Kanamori, H., J. Mori, and D. G. Harkrider, Excitation of atmospheric oscillations by volcanic eruptions, J. Geophys. Res., 99, 21,947-21,961, 1994.

Kelley, M. C., R. Livingston, and M. McCready, Large amplitude thermospheric oscillations induced by an earthquake, Geophys. Res. Lett., 12, 577-580, 1985.

Leonard, R. S. and R. A. Barnes, Jr., Observation of ionospheric disturbances following the Alaska earthquake, J. Geophys. Res., 70, 1250$1253,1965$.

Li, Y. Q., A. R. Jacobson, R. C. Carlos, R. S. Massey, Y. N. Taranenko, and $\mathrm{G}$. Wu, The blast wave of the Shuttle plume at ionospheric heights, Geophys. Res. Lett., 21, 2737-2740, 1994.

Liu, C. H. and K. C. Yeh, Excitation of acoustic-gravity waves in an isothermal atmosphere, Tellus, 23, 150-163, 1971.
Liu, C. H., J. Klostermeyer, K. C. Yeh, T. B. Jones, T. Robinson, O. Holt, R. Leitinger, T. Ogawa, K. Sinno, S. Kato, T. Ogawa, A. J. Bedard, and L. Kersley, Global dynamic responses of the atmosphere to the eruption of Mount St. Helens on May 18, 1980, J. Geophys. Res., 87, 6281-6290, 1982.

Lognonné, P., E. Clévédé, and H. Kanamori, Computation of seismograms and atmospheric oscillations by normal-mode summation for a spherical earth model with realistic atmosphere, Geophys. J. Int., 135, 388-406, 1998.

Nishida, K., N. Kobayashi, and Y. Fukao, Resonant oscillations between the solid Earth and the atmosphere, Science, 287, 2244-2246, 2000.

Ogawa, T., H. Kumagai, and K. Sinno, Ionospheric disturbances over Japan due to the 18 May 1980 eruption of Mount St. Helens, J. Atmos. Terr. Phys., 44, 863-868, 1982.

Otsuka, Y., N. Kotake, T. Tsugawa, K. Shiokawa, T. Ogawa, Effendy, S. Saito, M. Kawamura, T. Maruyama, N. Hemmakorn, and T. Komolmis, GPS detection of total electron content variations over Indonesia and Thailand following the 26 December 2004 earthquake, Earth Planets Space, 58, 159-165, 2006.

Pokhotelov, O. A., M. Parrot, E. N. Fedorov, V. A. Plipenko, V. V. Surkov, and V. A. Gladychev, Response of the ionosphere to natural and manmade acoustic sources, Ann. Geophys., 13, 1197-1210, 1995.

Roberts, D. H., J. A. Klobuchar, P. F. Fougere, and D. H. Hendrickson, A large-amplitude traveling ionospheric disturbance produced by the May 18, 1980, explosion of Mount St. Helens, J. Geophys. Res., 87, 6291$6301,1982$.

Row, R. V., Acoustic-gravity waves in the upper atmosphere due to a nuclear detonation and an earthquake, J. Geophys. Res., 72, 1599-1610, 1967.

Schunk, R. W. and A. F. Nagy, Ionosphere of the terrestrial planets, Rev. Geophys. Space Phys., 18, 813-852, 1980.

Shinagawa, H. and S. Oyama, A two-dimensional simulation of thermospheric vertical winds in the vicinity of an auroral arc, Earth Planets Space, 58, 1173-1181, 2006.

Tanaka, T., T. Ichinose, T. Okuzawa, T. Shibata, Y. Sato, C. Nagasawa, and T. Ogawa, HF-Doppler observations of acoustic waves excited by the Urakawa-oki earthquake on 21 March 1982, J. Atmos. Terr. Phys., 46, 233-245, 1984.

Tanioka, Y., Yudhicara, T. Kususose, S. Kathiroli, Y. Nishimura, S. Iwasaki, and K. Satake, Rupture process of the 2004 great SumatraAndaman earthquake estimated from tsunami waveforms, Earth Planets Space, 58, 203-209, 2006.

Walterscheid, R. L., G. Schubert, and D. G. Brinkman, Acoustic waves in the upper mesosphere and lower thermosphere generated by deep tropical convection, J. Geophys. Res., 108, A11, 1392, doi: 10.1029/2003JA010065, 2003.

Whipple, F. J. W., The great Siberian meteor and the waves, seismic and aerial, which it produced, Quart. J. R. Meteor. Soc., 16, 287-304, 1930.

H. Shinagawa (e-mail: sinagawa@nict.go.jp), T. Iyemori, S. Saito, and T. Maruyama 